\title{
Gender differences in relationship preferences after union dissolution
}

\begin{abstract}
Women less often repartner after union dissolution than men. To develop our understanding of this gender gap in repartnering, we look at men's and women's relationship preferences following the dissolution of marital and cohabiting unions. Using the Dutch Generations and Gender Survey Study ( $N=973)$, results show that divorced/separated women less often want to live with a partner again than men, and this holds for both singles and persons with a steady partner. Women's greater involvement with children from previous relationships largely explains the gender difference in the desire to live together. Men and women generally do not differ in their desire to marry, except when they cohabit. Cohabiting women express a weaker desire for remarriage than cohabiting men. Overall, we find women are less willing than men to proceed to the next step in a relationship - from dating, to living together, to marriage. Furthermore, there are gender differences in the way that structural factors shape preferences. Having (young) resident prior children affects women's preferences, whereas for men it is the frequency of contact with non-resident prior children that attenuates their desire to repartner. In addition, the examined factors have stronger effects on men's desire to marry than on women's.
\end{abstract}




\section{Introduction}

A divorce or separation is associated with many adverse consequences for the partners involved (see review by Amato, 2010). Remarriage or unmarried cohabitation after union dissolution (in short, repartnering) is considered to be an important "route to recovery" because it often increases people's economic and social-emotional well-being (Dewilde \& Uunk, 2008; Wang \& Amato, 2000). Yet, one of the most consistent findings is that women less often repartner than men (De Graaf \& Kalmijn, 2003; Ivanova, Kalmijn, \& Uunk, 2013; author identifying reference; Skew, Evans \& Gray, 2009; Wu \& Schimmele, 2005).

This gender difference in repartnering is most commonly accounted for by the greater structural restrictions that women face on the marriage market. For instance, women more often gain primary physical custody over the children than men thereby reducing women's opportunities to meet new partners as well as their ability to attract new partners because of the associated complexities of stepfamily life (Ivanova, Kalmijn, \& Uunk, 2013). Likewise, the pool of potential mates may in general be smaller for divorced women than men, as women face an age penalty in relationship formation and the supply of potential partners decreases with age for women only (Ní Bhrolcháin \& Sigle-Rushton, 2005). The gender gap in repartnering may, however, also be a matter of choice. How men and women experience relationships may be inherently different, with men benefiting more from relationships than women (e.g. Bernard, 1982 [1972]; Waite \& Gallagher, 2000). Women may therefore be more reluctant to enter a subsequent union (author identifying reference ). Little is known about the desires of divorced and separated people (but see Parker, 1999), however research about widowhood suggests that choice is an important element in the gender disparity in repartnering following widowhood: widows indicate that they do not want to repartner because they are not willing to give up their newly acquired freedom to once again take care of a household and a man (Davidson, 2002; De Jong Gierveld, 2002). 
In this study, we examine people's relationship preferences after union dissolution and aim to gain more insight into the possible gendered nature of these preferences. Most research about repartnering following union dissolution has simply documented a gender difference in the rates of repartnering (e.g, Ivanova, Kalmijn, \& Uunk, 2013;; Wu \& Schimmele, 2005). Some research provides tentative explanations for the gender gap in repartnering, but offer limited insight into the sources of this gender difference as almost all studies examine the correlates of repartnering separately for each gender (De Graaf \& Kalmijn, 2003). If explanations for gender differences in repartnering are explored, the role of structural factors, such as parenthood, in explaining the gender gap in repartnering rates are examined without disentangling whether these structural factors affect people's repartnering behavior via the restrictions they impose or the choices people make (e.g., Ivanova, Kalmijn, \& Uunk, 2013). In fact, these structural factors are often interpreted in terms of the barriers they represent on the marriage market rather than in terms of shaping people's preferences (ibid). Although we cannot unravel the complex interplay between preferences and restrictions on the likelihood of repartnering, our study develops our understanding of repartnering processes, by focusing on relationship preferences after union dissolution, a factor that is particularly likely to influence people's repartnering decisions

First, we examine whether men and women still desire to live with a partner and get married in the future (in short, desire to repartner) after their previous marriage or cohabitation has ended. If women less often want to repartner than men, this would suggest that women's lower repartnering rates are not only a matter of greater restrictions - as has most commonly been suggested - but that they may in part be driven by choice. Second, we examine how structural factors - such as economic resources and parenthood - shape people's preferences and whether these factors can account for any gender differences in relationship preferences (mediation). The factors included in this study are similar to those commonly 
included in research on repartnering. If these factors shape people's preferences, this would suggest that they affect chances of repartnering not only via the restrictions they impose but also via choice related processes - although we acknowledge that restrictions may shape people's preferences. More importantly, as many of the factors associated with repartnering are known to differ greatly between men and women, they may partly account for any observed gender difference in relationship preferences. We, in particular, examine whether differences between men and women in their economic resources, their involvement with children from previous relationships and in their current romantic attachments can account for gendered preferences. Third, we study whether the influence of structural factors differs between men and women (moderation), as some studies on repartnering show that effects vary by gender.

As far as we are aware, there is very little research on the partnering preferences of divorced and separated men and women. Existing studies about relationship preferences have either focused on a more general sample, including never married persons for instance (e.g., Frazier et al., 1996) or they focused on the relationship preferences of widowed persons (e.g., Carr, 2004). An exception is an Australian study by Parker (1999). She finds that divorced and separated men have a greater interest than women in forming a new relationship and that the factors associated with this desire are gendered. However, she does not explore the sources of the gender difference and her findings are based on a small sample of unattached persons. We extend this previous work in several respects. First we use large-scale data from the Netherlands. Second, we include cohabiting men and women as well as those in steady non-residential partnerships (living apart together relationships) when examining the desire to marry. It is important to extend the sample beyond single persons, because those in living apart together relationships are at risk of cohabitation or marriage and cohabitors are at risk of marriage. More importantly, living-apart-together relationships and cohabitation may have 
become viable alternatives for remarriage among divorced or separated people (Wu \& Schimmele, 2005), which is likely to be expressed in their relationship preferences. Finally, we include more detailed measures of economic resources, involvement with prior children and current romantic attachments than earlier studies on repartnering to provide further insight into gender differences in repartnering preferences.

\section{Structural factors, gender and relationship preferences}

Men and women who divorced or separated vary greatly in certain background characteristics, most notably in: (a) their levels of economic resources, (b) their involvement with children from a previous relationship, and (c) their romantic attachments (before moving on to cohabitation or marriage). These structural factors may also shape people's partnering preferences, in turn leading to a gender difference in these preferences.

Women have fewer economic resources after union dissolution than men: they have lower income and participate less in the labor market (Aassve, Betti, Mazzuco, \& Mencarini, 2007; Andreß et al., 2006; author identifying reference). It is unclear beforehand whether this economic gender disparity leads to a weaker or stronger desire to repartner among women than men. First, economic resources may affect preferences indirectly via their association with people's perceived chances of success in finding a new partner. People may have less desire to repartner if they don't think they will find a partner - so preferences may reflect perceived or real restrictions in the marriage market. Although results are not always significant, research suggests that high-resource men and women are more likely to repartner (Lampard \& Peggs, 1999; author identifying reference; Sweeney, 1997). Hence, they may also be more optimistic about their repartnering prospects, in turn leading to a stronger preference for repartnering vis-à-vis those with few such resources. Second, a certain minimum of economic resources is required for household formation (Oppenheimer, Kalmijn, 
\& Lim, 1997). Hence, people with few economic resources may simply not be able to afford to establish a new household, which leads them to adjust their desires for repartnering accordingly. Although this argument was traditionally reserved for men, the equalization of men's and women's contributions to the household income suggests that the argument may also hold for women nowadays (Oppenheimer, 1988).

Third, and contrary to the previous argument, persons with few economic resources may have stronger desire to enter a new relationship to improve their economic security (Kalmijn \& De Graaf, 2003). Although this argument is most often applied to women, reduced gender role differentiation suggests that this argument may nowadays also hold for men. The scant evidence so far does not support either of the contradictory expectations, as economic resources have been found to bear little association with relationship preferences (Parker, 1999). We therefore refrain from hypotheses about the effects of economic resources on relationship preferences, the gender difference in relationship preferences resulting from the economic gender differences, and the mediating role of economic resources to explain gender differences in preferences.

Another aspect in which men and women differ is the extent to which they continue to be involved with their children from previous relationships. Mothers more often gain physical custody (Kelly, 2007) and will likely have more contact than men with children living outside the household (be it living with the ex-partner or on their own) as women generally tend to more often keep contact with kin (Rosenthal, 1985). Involvement with children from previous relationships may in turn affect relationship preferences. First, children are likely to be a barrier to repartnering. The care for children restricts the time that can be spent on searching for a new partner and potential partners may be deterred by the prospect of becoming a stepparent (Ivanova, Kalmijn, \& Uunk, 2013). Research shows that prior children reduce chances of repartnering, especially these of women (Beaujouan, 2012; Ivanova, Kalmijn, \& 
Uunk, 2013; Lampard \& Peggs, 1999; author identifying reference). To the extent that people are aware of these greater restrictions and adjust their aspirations accordingly, this would imply a weaker preference for repartnering among those with prior children, particularly if they have a high level of involvement with those children. Second, children may also directly affect people's relationship preferences. Parents, especially those with high levels of childrearing responsibilities, may be more cautious when entering into a new relationship for the sake of the children: children for instance may find it difficult to accept a new partner. A more prosaic reason for being reluctant to enter a co-residential union, is that the amount of child support to be paid or received may be adjusted as the income of a new partner may be taken into account when calculating child support (references). In contrast, it is also possible that prior children may increase the desire for a new partner, because extra income and support may be especially welcome when raising dependent children (Kalmijn \& De Graaf, 2003). There is, however, little empirical evidence for this argument, as previous research shows that having two or more children reduced the desire for a new relationship among women (Parker, 1999). We thus hypothesize that greater involvement with prior children reduces the desire to repartner. Because women are more likely to have primary custody and be more involved with prior children, we also expect that women with children will have less desire to repartner than men. This implies that women's weaker desire to repartner is (partly) explained by their greater involvement with prior children.

Finally, men and women may differ in the extent to which they are already in a steady (co-residential) relationship. As addressed in the introduction, most research finds that women repartner less than men. Even when background characteristics are taken into account, women may still be at a disadvantage on the dating and marriage market vis-à-vis men. For instance, the pool of suitable partners is likely to be smaller for women than men after union dissolution (Ní Bhrolcháin \& Sigle-Rushton, 2005; England \& McClintoc, 2009) and men 
tend to be less willing to marry a divorced partner than women (South, 1991). Women are therefore expected to be less often cohabiting or in a steady relationship than men after a union dissolution, and when they are it may be of lower quality as suggested in the literature on the consequences of shortages on the marriage market (Lichter, Anderson, \& Hayward, 1995). A person's current relationship status may in turn affect the desire to repartner, but it is unclear how. People who are in a steady dating relationship have already overcome the restrictions on the repartnering market, so they are likely to be more positive about their chances of actually living together or marrying in the future. This will be all the more true for those in a high quality relationship. In addition, the prospect of getting married or entering cohabitation may have become less hypothetical leading to a stronger desire among those with (high-quality) relationships. The same argumentation goes for cohabiters and their desire to marry. A counterargument is that people with a steady non-residential or a cohabiting relationship regard this as the end-station. Divorced persons, for example, may be reluctant to re-enter a committed relationship such as marriage again given their previous experiences. Cohabitation is indeed popular among divorced and separated persons (Wu \& Schimmele, 2005). This line of reasoning suggests a weaker desire for repartnering among those in a steady non-residential or cohabiting relationship. Because of these contradictory expectations, we refrain from hypotheses.

Other factors besides economic resources, prior children and relationship status may affect relationship preferences as well, but these are not likely to vary that much between men and women. Hence, these factors will be relatively unimportant for the association between gender and relationship preferences. Most notably, the type of union dissolution, age and religiosity will likely affect the desire to repartner. Research suggests that former cohabitants repartner at a faster rate than previously married persons (author identifying reference; Stewart, Manning, \& Smock, 2003; Wu \& Schimmele, 2005). Divorced people may be more 
cautious to enter a new relationship, because a failed marriage, with its greater investments, probably hits harder than a failed cohabitation. Parker (1999) finds that formerly married men more often express no interest in a new relationship than men who cohabited, yet no association was found for women. Older people also have a weaker desire to repartner (South, 1991; Van Hoorn, 2000). This may not only arise from their more restricted marriage market opportunities leading older people to adjust their aspirations downwards, but also because age may temper the desire for a partner per se. Older single people may have found other ways to live a fulfilling life without necessarily needing a partner (author identifying reference). Furthermore, religiosity may matter but its role is ambiguous (De Graaf \& Kalmijn, 2003). Because many religions are pro-marriage, religious men and women will probably have a stronger desire to remarry than their non-religious counterparts and less desire for cohabitation (ibid.).

\section{The role of gender}

Women and men may also experience relationships differently. A marriage may actually consist of two marriages, his and hers (Bernard, 1982[1972]), with his marriage being better than hers. Although recent findings on his and her marriage are inconsistent (see review by Carr \& Springer, 2010), this would imply that women might be more careful than men the second time around (author identifying reference), with women having a weaker desire to repartner than men. In addition, some research shows that the social-psychological impact of union dissolution is stronger for women than men (Willitts, Benzeval, \& Stansfeld, 2004; author identifying reference). Given this greater impact, we would also expect women to be more cautious when repartnering. Available evidence suggests that divorced/separated women have less desire to repartner than their male counterparts (Parker, 1999; Frazier et al., 1996), but this research did not take into account any gender differences in structural background 
characteristics when assessing whether men's and women's preferences differ after a breakup. We nonetheless expect that women have less desire to repartner than men, once differences in background characteristics are taken into account.

We also expect gender to moderate the influence of structural factors on relationship preferences. That is, the association between background characteristics, on the one hand, and relationship preferences on the other, may differ between men and women.. Family research typically finds that many background factors have a stronger impact on women's family outcomes than men's, be it for instance work-family balance (Roxburgh, 2002), perceived marital problems (Amato \& Rogers, 1997) or divorce initiative (author identifying reference). This may be explained by the fact that women are in general more sensitive to relationship issues than men (Amato \& Rogers, 1997). Parker (1999) also showed that many of the factors that were examined significantly affected women's, but not men's, desire for a new relationship. She points at the more difficult and insecure circumstances of women following union dissolution as a possible explanation, making women more aware of the many issues involved when one were to repartner again (Parker, 1999: 43). We thus expect that the effects of the examined factors on the desire to repartner are stronger for women than for men.

\section{Method}

We use data from the first wave of the Dutch Generations and Gender Surveys (also known as the Netherlands Kinship Panel Study - NKPS; Dykstra et al. 2005). This is a large survey conducted between 2002 and 2004. The sample was drawn randomly and is representative with respect to region and urbanization. The response rate was $45 \%$, which is comparable to the response rates of other Dutch family surveys - a country known for a lower public willingness to participate in surveys (De Leeuw \& Heer, 2001). Women, people in the middle age ranges, and those with children living at home were found to be overrepresented (Dykstra 
et al. 2005). The data are therefore weighted in the descriptive analyses with weights adjusting with respect to household type, gender, age, region and urbanization. The data comprise 8,161 respondents who were interviewed face-to-face and in addition, they filled in a self-administered questionnaire. About $92 \%$ of the respondents returned the questionnaire (Dykstra et al. 2005).

To examine gender differences in the desire to live with a partner or to marry after union dissolution, we selected men and women who had experienced the dissolution of a marriage or a cohabiting relationship and who were not co-residing with a partner $(n=1,244)$ or who were cohabiting at Wave $1(\mathrm{n}=340)$. Note that the group of respondents who do not co-reside with a partner includes singles as well as people with a steady partner with whom they do not co-reside. We further restricted the sample for analysis. Widowed people $(n=65)$ were excluded. In addition, we excluded respondents of 65 , the official retirement age, and older, because these people likely face a different remarriage market than younger persons, due to the loss of social roles (Van Tilburg, 2006) and the higher and gender specific mortality rate among elderly people $(n=122)$. We also excluded respondents with inconsistent information about the desire to life together and desire to marry. As will be explained in more detail in the measurements section, this means that we excluded those who indicated that they did not want to live together and yet did want to get married $(n=15)$. Finally, we selected only those men and women for whom the union dissolution was ten years ago or less (excluded $n=409$ ). Older divorce cohorts may have faced quite a different remarriage market, because only since the 1990s Dutch divorce rates no longer increased, suggesting that at that time divorce was really becoming more 'normalized'. This selection also enables us to avoid our results being disproportionally influenced by a group who never repartners, because this group is likely to be overrepresented in a cross-sectional sample due to the fact that people who are already repartnered are not in the sample. 
The eventual sample consists of 973 persons (596 women and 377 men). Of this total sample, 762 (297 men and 465 women) were not co-residing and this sub-sample is used for the analyses of the desire to live together (Sample 1). Sample 1 consists of both singles and people with a steady partner with whom they are not living together. The sub-sample for the analyses of the desire to marry (Sample 2) includes 648 respondents (271 men and 377 women). Sample 2 includes not only people who are single or who have a steady partner with whom they do not co-reside, but also includes cohabiting persons, as they are at risk of marriage as well.

\section{Measures of the dependent variables}

We examine two dependent variables; the desire to live together and the desire to get married. The desire for living together was asked only of respondents who were not co-residing with a partner, although they may have had a steady partner with whom they did not live together. They were asked: “Would you like to live together with a / your partner in the future?". The answering categories were yes, no and don't know. Respondents who answered "yes" are given a score of 1 (and 0 otherwise). For the second dependent variable, respondents who were not married and were either cohabiting or with a steady partner in a non-residential union were asked "Would you like to marry in the future?" (yes, no and don't know). Based on this information, a dichotomous variable for the desire to marry was constructed (1 = yes). We exclude those who do not want to live with their partner from the second dependent variable because marriage usually implies that partners co-reside. A further examination of the sample, however, identified some respondents who indicated that they do want to marry, yet do not want to live together. It may be that these respondents interpreted the question about living together as a question about unmarried cohabitation - although the question does not use the Dutch term for unmarried cohabitation but rather the more general term of living 
together. To avoid biases from such misinterpretations, these respondents were excluded from the measure of the desire to get married $(n=15)$.

\section{Measures of the independent variables}

Gender. A dichotomous variable coded 1 if the respondent is a woman and 0 if male.

Economic resources. Our first measure of economic resources is a respondent's level of education, originally ranging from $1=$ unfinished primary school to $10=$ post-academic, and recoded to the formally required years to obtain this level of education (ranging from 4 to 20 years). Our second measure is a respondent's personal net monthly income, which is the sum of income from paid employment and social benefits. Income is divided by 1000 to prevent small estimates in the analyses. The third measure is the number of hours that respondents work per week. If they do not have a job respondents were assigned 0 hours.

Prior children. The presence of prior children is captured by two variables indicating (a) whether the respondent had prior children living in the household, and (b) if not, living somewhere else - the reference group being those who do not have children from prior relationships. The first variable indicates whether respondents had children from previous relationships living in their households (1 if yes), that is whether a prior child lived with the respondent for at least two days a week. The second variable indicates that all of respondent's prior children live outside the household (be it with the ex-partner or on his/her own). In addition, a variable indicating the age of the youngest child living in the household was constructed (in years). The mean was assigned to those without prior children residing in the household. Also, we constructed a variable indicating the frequency of contact with nonresident children, measured as the number of times a year that the respondent had face-to-face contact with prior children (averaged over all of his/her children). And finally, we constructed a variable indicating whether child support was being paid or received (1 if yes). Numbers 
were too few to distinguish payment from receiving child support, but figures show that women most often receive and men most often pay child support.

Relationship status. First, we constructed a variable indicating whether respondents had a steady partner. Respondents were asked whether they currently had a partner with whom they had a relationship for at least three months. If so, they scored 1 on this dichotomous measure. Second, we constructed a variable whether respondents were cohabiting (included in the analyses for the desire to marry, $1=$ yes). Third, we constructed a variable measuring the relationship quality of those who had a steady (co-residential) relationship. The mean score on four items measuring the extent of agreement with statements about the relationship was taken. Cronbach's alpha was high (.95). Examples of relationship items are "We have a good relationship" or "The relationship with my partner makes me happy".

The analyses control for duration since the last union was dissolved (in years), the type of union that was dissolved (marriage $=1$ and cohabitation $=0$; if respondents experienced both kinds of union dissolutions, they got a score of 1), age (in years), and religiosity, a dummy indicating whether respondents felt they belonged to a church or religion (1 if yes). Because in wave 2 religiosity was asked in the interview instead of the selfadministrative questionnaire (as was done in wave 1), part of the missing values (originally $11 \%$ ) could be solved by using information from wave 2 . The remaining missing values (5\%) were imputed by means of multiple imputation.

Table 1 shows the descriptive statistics of the independent variables for men and women separately for each sub-sample. The last column shows whether men and women differ significantly on these variables. Women have significantly fewer economic resources than men, as they have less income and work fewer hours. Women also are more involved with prior children: they more often have children living with them, especially younger children, and have more contact with non-resident children. Hence, these factors may mediate 
any gender difference in relationship preferences. Surprisingly, no significant differences were found in the relationship status of men and women. Part of the explanation may be that we do not look at instantaneous rates of repartnering but rather at cross-sectional percentages that result from dynamic processes of entry into and out of relationships. If women were to stay longer in relationships than men, or would less often move on to cohabitation, this could result in a higher cross-sectional percentage of women in a (residential) relationship and thus smaller gender differences, despite women's lower chances of entering a relationship. Our data indeed suggest that this may be the case, as women have more often experienced just one union dissolution than men (74 versus $67 \%$ ). When it comes to the control variables, women are found to be significantly younger and more often religious than men.

\section{[Here Table 1]}

\section{Analytical strategy}

First, we show descriptive results of men's and women's relationship preferences to examine whether there is a gender difference in relationship preferences after divorce or separation. To put the findings into perspective, we include descriptive statistics of comparable men and women who never experienced a union dissolution.

In the second step we run two separate analyses. The first examines respondents' desire to live together. For this analysis a subsample (Sample 1) of 762 respondents who were not co-residing (but may or may not have a steady partner) were used. In the second analysis we examine the desire to marry, using a subsample (Sample 2) of 648 respondents. This sample also includes cohabiting persons $(\mathrm{n}=211)$, but excludes those who did not want to live together $(n=325)$, because all these people also do not want to get married (as marriage implies living together). The second analyses examining whether the respondents want to marry or not are thus conditional upon whether a person indicated they were willing to live 
with a partner.

For both analyses we estimated several logistic regression models. In the first model, only the controls and gender are included. This model shows the overall gender difference in relationship preferences. In the second model, the variables measuring economic resources are included to see whether these can explain away any gender difference (mediation). In the third and fourth model, the variables relating to prior children and the variables measuring relationship status, respectively, are included. In the fifth model, all variables are included. These models are being estimated for the full sample and the first and fifth model are also estimated for singles and respondents with a partner (LAT and/or cohabiting) separately, to explore whether processes are different depending upon whether people have a partner or not.

In the third step, the fifth full model is estimated separately for men and women to see whether the examined factors are differently associated with relationship preferences for men and women (moderation). We also test whether the estimates differ significantly for men and women by including interaction terms between gender and all independent variables, but it should be noted that the power of these tests is not that high, given the relatively low number of cases, especially for men.

Although there were no missing values for the dependent variables, there were missing values on the independent variables. Non-response was generally low $(<1 \%)$, except for income (5\%) and variables that were asked for in the self-administrative questionnaire (i.e., religiosity (11\%) and relationship quality (11\%). Multiple imputation was used to deal with missing values in all models (mi impute in Stata 12).

\section{Results}

Figure 1 visualizes the relationship preferences of separated and divorced men and women and compares these to those of men and women who never dissolved a union. It shows first 
that divorced and separated persons less often want to repartner, be it living together or marrying, than persons who have not experienced a union dissolution. The left side of the graph shows the results for the desire to live together. The majority of men ( 80 percent) and women (78 percent) without any prior dissolution experiences want to live together with a partner in the future, but only 66 percent men and 57 percent of women who divorced or separated want that to happen. Similarly, 66 percent of men and women who never experienced a union dissolution want to marry, and these figures go down to 47 percent and 53 percent, respectively, for the divorced/separated group. Second, for both outcomes, gender differences are virtually non-existent for the group who never divorced or separated, but there are some gender differences among those who previously divorced or separated. We find that divorced and separated women are significantly less likely to express a desire to live together than their male counterparts $(\mathrm{t}=2.304 ; \mathrm{p}=.022)$.

\section{[Here Figure 1]}

Next, we examine which factors account for the observed gender difference in the desire to live together. Table 2 shows the results of the sequence of logistic regression models that were estimated to examine the possible mediating role of economic resources, prior children and current relationship status. Models were estimated for the full sample and for singles and people with a LAT partner separately. Starting with the full sample, Model 1 (M1) again shows a significant gender difference, once the control variables are taken into account. The odds of wanting to live with a partner are $48 \%$ ([1- exp(-.653]*100\%) lower for divorced and separated women than for their male counterparts. Model 2 (M2) also includes the indicators for a person's economic resources. The estimate for gender decreases but is still significant. This is not surprising given that few economic resources significantly impacted on preferences in model 2 . Only education level significantly affects the desire to live together with higher educated persons being more likely to express a desire for living together. Yet, 
men and women were not found to differ in their attained education (see Table 1), and therefore while significant the mediating role of education is small. In model 3 the variables relating to prior children are added to model 1 . The magnitude of the estimate for gender becomes smaller. Women were found to be more involved with children from prior relationships, especially younger children (see Table 1). The estimates in model 3 show that greater involvement is strongly associated with less desire to live together. Respondents with children from previous relationships residing with them in the household have significantly lower odds of wanting to live together than those with no prior children (59 percent). Older children are associated with a greater desire to live together. Although no significant differences are found between persons with prior children living outside of the household and those with no prior children, the frequency of contact with these non-resident children matters. The more often people see their non-resident children from previous relationships, the less desire they have to live together with a/their new partner. The financial aspects of children do not seem to matter: child support is not significant. Even if the greater involvement of women with their prior children is taken into account, however, there is still a significant gender difference with the odds of wanting to live together being 31 percent lower for women as compared to men.

In model 4 the variables related to a person's current relationship state are added. As expected on the basis of the non-significant and small differences between men and women in their relationship status (see Table 1), the mediating role of current relationship status is negligible. The estimate for gender is more or less the same as that in model 1 . The relationship variables are, however, significant. Persons with a steady relationship and those with higher quality relationships are more likely to indicate that they want to live together than those without a relationship or low quality relationships.

Finally, in model 5 we see that inclusion of all variables together render the estimate 
for gender to non-significance. The estimates for economic resources, prior children and relationship status are generally the same as in the previous models, be it a bit smaller. Only the significant effect of education found in model 2 disappears once the other factors are taken into account. When it comes to the controls, we further see that age and religiosity matter, where younger and more religious people are more likely to want to live together in the future.

\section{[Here Table 2]}

Next, we estimated models 1 and 5 for singles and people with a steady, non-residential partner separately. Results with respect to the role of gender are remarkably similar and fully interacted models, with all variables being interacted with partner status (results not shown), also show that the effects of gender do not differ between singles and people with a partner in both models 1 and 5. Note, however, that the number of people with a partner is low which reduces the power of our analyses. This similarity suggests that even when women find a new steady partner, despite their presumably lower chances of being successful in their search, they still have less desire to live together than men (see M1). When resources and prior children are controlled for, gender differences become smaller and not significant for partnered people and singles (M5). Although estimates for resources, prior children and the controls seem stronger for singles, fully interacted models show no differences between singles and partnered individuals in these estimates.

Table 3 shows the different models for the desire to marry. Consistent with the bivariate analyses (see figure 1), results for the full sample show that there are no significant differences between men and women in their desire to marry. This suggests that once people want to live together, men and women are equally likely to express a willingness to get married in the future. This is true for all the models that we estimated for the full sample. Interestingly, financial aspects of having prior children matter when it comes to the desire to 
marry, but not children's residence and contact with children. People who pay or receive child support are less willing to marry. Other characteristics that are found to affect people's desire to marry are whether they are engaged in a steady relationship (albeit only borderline significant), their age, the time since union dissolution and religiosity. Those who have a steady relationship have a stronger desire to marry than people without a relationship, this is also the case for younger people, those whose union dissolved longer ago, and more religious persons.

\section{[Here table 3 and 4]}

In the last columns of Table 3, we explore whether results differ between singles and people with a steady or cohabiting partner. Gender differences appear to be in opposite directions for single and partnered individuals, with fully interacted models with partner status (results not shown) showing a significant difference in the effect of gender (for both M1 and M5). Due to the low numbers per group, gender effects are not always significant, but results suggest that among single individuals, women appear to be slightly more willing to marry, whereas the reverse holds for partnered individuals. Gender differences are more or less similar regardless of whether resources and prior children are controlled for in both the single and partnered group. In additional analyses (not shown), we split the partnered group in those with a nonresidential partner and those with a cohabiting partner. For both models 1 and 5, we find that gender differences are small and not significant for those with a nonresidential partner, whereas gender differences are significant for people who cohabit $(b=-.663(p=.042)$ in M1 and $b=-.658(p=.100)$ in M5). Thus cohabiting women in particular are less likely to express a desire for marriage than cohabiting men. Focusing on the complete model (M5), results for the other variables are more or less similar to those for the full sample; child support, age, duration since union dissolution and religiosity are significantly related to the desire to marry, and for singles, a higher level of contact with nonresident children lowers the 
desire to marry. Estimates seem larger and more often significant for singles, but a fully interacted model (not shown) shows that only the estimate for contact with nonresident children differs between singles and persons with a partner. Note, however, that the number of cases is small.

Finally, in table 4 we examine whether the effects differ for women and men. We expected that the effects of background characteristics would be stronger for women than men. When looking at the results for the desire to live together, the findings are mixed. Some effects are stronger and only significant for women, whereas other effects are stronger and significant only for men. Most notably, current relationship status only affects women's desire to live together, not men's, and the same holds for religiosity. For women only, those with steady and higher quality relationships and those who are religious, are more likely to want to live together. Economic resources and prior children are associated with both men's and women's preferences, but in a different way. With respect to the role of economic resources, it is income that matters for men's desire to live together, whereas it is educational level for women, with higher income men and higher educated women wanting to live together more often than their lower income and lower educated counterparts. For women, having a young child from a previous relationship living with them in the householdreduces their desire to live together, whereas for men it is frequent contact with non-resident children from previous relationships that makes them less willing to live together again. Although the low number of cases reduces the power of the models, fully interacted models with gender (not shown) show that only the effects of income and contact with nonresident children differ significantly between men and women.

The results for the desire to marry (see last columns Table 4), show a more consistent pattern. Contrary to our expectations, most factors bear a stronger (instead of weaker) association with men's desire to marry than with women's. For women, we only find a strong 
and significant effect of age: older women less often want to marry than younger women. The negative effect of age is, however, significantly stronger for men (results of the interaction model not shown), and for men more factors are important for their desire to marry as compared to women. Men with higher income are more willing to marry than lower income men and in this respect they differ significantly from women (not shown), where income appears to have the opposite effect (be it borderline significant). The results also suggest that men who are in a steady or cohabiting relationship increases men's, not women's, desire to marry, and the same holds for being religious or having been divorced/separated for a longer time - but these effects do not differ between men and women (interaction models not shown).

\section{Discussion}

A well-established finding is that women less often marry or cohabit with a new partner after union dissolution than men (Sweeney 2010). To develop our understanding of why women repartner less, this study examined people's relationship preferences and the gendered nature of these preferences, using large scale survey data from the Netherlands.

Our findings suggest first that women's lower repartnering rates may in part be a matter of choice. The gender gap in repartnering has often been attributed to the greater restrictions faced by women on the remarriage market (e.g., Ivanova, Kalmijn, \& Uunk, 2013), but our study found that women also have less desire than men to live together again. In contrast to those who had not experienced separation or divorce, large gender differences were observed among divorced or separated persons in their desire to live with a new partner in the future. Whereas about two thirds of the men wanted to live together, little over 55 percent of women expressed such a desire. The observed gender difference in the desire to live together corroborates Parker's finding (1999) that women were less interested in a new 
relationship than men after relationship breakup. Our percentages are actually quite similar to hers (65 and 43 percent), despite differences in the country, sample criteria and measures.

The possible role of choice for women's lower repartnering rates is further corroborated by the finding that these gender differences are not only found for single persons but also for persons with a steady partner. For single women one could argue that their weaker desire may in part be due to the greater restrictions faced by women on the remarriage market, but this argument is less valid for women with a partner, who have overcome these restrictions. So even when women have overcome the gendered restrictions in the dating market, they still have less desire to live together than men

Once people wanted to live together, though, men and women did not differ significantly in their desire to marry. This suggests that women find the prospect of moving in together rather than marrying less desirable than men. An important qualification to this general conclusion is that partner status matters: whereas little gender differences are found for singles, women with a partner, especially cohabiting women, are less willing to marry than their male counterparts. Together, our findings suggest that women are less willing than men to proceed to the next step in a relationship (form dating, to living together, to marriage), which may in part explain their lower overall levels of repartnering.

Secondly, our study points at the pivotal role of prior children in explaining people's relationship preferences and in explaining why women have less desire to live together. Children from previous relationships were found to be one of the strongest determinants of people's relationship preferences, but the associations differed between wanting to live together and to marry. The desire to live together was associated with the amount of time parents spent with their children and not with the financial aspects of having prior children, whereas the reverse was true for the desire to marry. Resident children, in particular of a young age, attenuated the desire to live together and so did frequent contact with non-resident 
children from previous relationships. These factors were not related to the desire to marry, but child support did affect the wish to marry: people who paid or received child support were less likely to express a desire for remarriage. The greater role of child support for the desire to marry may be explained by legal and administrative differences between marriage and cohabitation, resulting in a higher likelihood of child support adjustments in case of remarriage.

Prior children were also central in explaining the gender difference in the desire to live together. Because women were more involved with their prior children than men, their weaker desire for living together could partially be explained by this greater involvement. Women's fewer economic resources did not explain women's weaker desire to live together, because people's desires were hardly affected by their economic resources. Also their current relationship status could not explain why women have less desire to live together. Although people with a steady partner and those with better quality relationships more often wished to live together, men and women did not differ from each other in these respects. Once all structural factors were taken into account, women were no longer found to be less willing to live together than men.

The central role of prior children in shaping people's partnering preferences and in explaining the gender gap is consistent with earlier studies on repartnering (Beaujouan, 2012; Lampard \& Peggs, 1999; Ivanova, Kalmijn \& Uunk, 2013). Our study underscores that women's greater caring responsibilities are key to their lower repartnering rates, not only because children are a barrier on the marriage market - as research has already suggested but also because children influence people's choices. Although preferences may partly reflect restrictions, it is also very likely that people are hesitant to repartner for the sake of the children, as it may be difficult for them to accept, or because financial considerations relating to changes in child support may attenuate people's desire to repartner. 
Third, the way that structural factors shape people's relationship preferences was found to be gendered. For the desire to live together, the findings were mixed but a notable finding was that involvement with prior children was differently associated with the desire to live together for men and women. For women it was resident children from previous relationships, particularly young children that made them less likely to want to live together, whereas it was frequent contact with non-resident children that was important for men. This finding mirrors standard custody arrangements with mothers more often obtaining physical custody over the children and fathers becoming non-resident parents with visitation arrangements. Our finding that prior children are also important for men's desires to repartner, offers some insight in the so far inconclusive evidence about whether or not having prior children parenthood affects men's chances to repartner (see review by Ivanova, Kalmijn \& Uunk, 2013). Most previous studies on repartnering only included indicators for parenthood or the residence of prior children. Our findings suggest that the amount of contact with nonresident children was more important for men's preferences than whether they had prior children, be it living outside or inside their household. This suggests that some of the inconsistencies observed in previous research may be due to the use of limited indicators. We therefore strongly encourage research that takes into account the level of contact with nonresident children to examine its relevance for men's actual repartnering behavior. This is all the more important given that most fathers are (still) the non-resident parent: contact with non-resident children reflects the day-to-day reality of parenthood for most men.

Unexpectedly, men's desire to marry depended more on structural factors than women's. For women, only age was important with older women having less desire to marry. In contrast, men's desire to (re)marry was also stronger if they had higher incomes, were in a romantic relationship, were younger, religious and when they broke up a longer time ago. The stronger associations for men are contrary to previous literature and we can only speculate 
about these contradictory patterns. It may be that the big step for women is moving in together with a new partner, whereas for men it is getting married. This is consistent with Davidson's study among widowed persons, suggesting that men and women have different expectations about relationships: 'for women it was the wish for companionship outside, and for men, inside the home' (Davidson, 2002: 51). For men the big decision may be whether or not to (re)marry, perhaps because of the legal implications it involves or because of the greater interpersonal commitment it signifies. The decision to marry may be so important that the pros and cons are particularly salient. As these pros and cons depend upon many of the structural factors we examined, such factors may be particularly important for men's desire to marry. Further research is needed to examine whether men and women indeed have different perceptions of the importance of living together and marriage.

This study focused on preferences only and could not unravel the complex interplay between restrictions, preferences and repartnering. In addition, our study used a crosssectional design, probably containing an overrepresentation of men and women who indicate that they do not want to repartner. Prospective data following people right after divorce or separation, which include measures for relationship preferences and repartnering are needed to overcome both limitations. Ideally, these data would include measures for whether people want a partner (without necessarily living together or getting married) and whether they have a steady partner. Most of our knowledge about repartnering relates to co-residential relationships, but living-apart-together relationships may be a likely alternative to such relationships, especially for divorced and separated women as our study suggests. To our knowledge, such data are not available. Our study is therefore an important first step in that it is one of the first studies to show that choice may be an important element in explaining why people don't remarry and in particular, why women repartner less than men. 


\section{Acknowledgements}

The Netherlands Kinship Panel Study is funded by grant 480-10-009 from the Major

Investments Fund of the Netherlands Organization for Scientific Research (NWO), and by the Netherlands Interdisciplinary Demographic Institute (NIDI), Utrecht University, the University of Amsterdam and Tilburg University. 


\section{References}

Aassve, A., Betti, G., Mazzuco, S., \& Mencarini, L. (2007). Marital disruption and economic well-being: A comparative analysis. Journal of the Royal Statistical Society: Series A (Statistics in Society), 170(3), 781-799.

Amato, P. R. (2010). Research on divorce: Continuing trends and new developments. Journal of Marriage and Family, 72(3), 650-666.

Amato, P. R., \& Rogers, S. J. (1997). A longitudinal study of marital problems and subsequent divorce. Journal of Marriage and the Family, 59, 612-624.

Andreß, H. J., Borgloh, B., Bröckel, M., Giesselmann, M., \& Hummelsheim, D. (2006). The economic consequences of partnership dissolution - a comparative analysis of panel studies from Belgium, Germany, Great Britain, Italy, and Sweden. European Sociological Review, 22(5), 533-560.

Beaujouan, E. (2012). Repartnering in France: The role of gender, age and past fertility. Advances in Life Course Research, 17(2), 69-80.

Bernard, J. (1982). The Future of Marriage, 2nd Ed. New York: Bantam Books.

Carr, D. (2004). The desire to date and remarry among older widows and widowers. Journal of Marriage and Family, 66(4), 1051-1068.

Carr, D., \& Springer, K. W. (2010). Advances in families and health research in the 21st century. Journal of Marriage and Family, 72(3), 743-761.

Davidson, K. (2002). Gender differences in new partnership choices and constraints for older widows and widowers. Ageing International, 27(4), 43-60.

De Jong Gierveld, J. (2002). The dilemma of repartnering: Considerations of older men and women entering new intimate relationships in later life. Ageing International, 27(4), $61-78$. 
De Graaf, P. M., \& Kalmijn, M. (2003). Alternative routes in the remarriage market: Competing-risk analyses of union formation after divorce. Social Forces, 81(4), 14591498.

De Leeuw, E. D. \& De Heer, W. (2001) Trends in household survey nonresponse: A longitudinal and international comparison. In Groves, R. M., Dillman, D. A., Eltinge, J. L. \& Little, R. J. A. (Eds) Survey Nonresponse (pp. 41-54). New York: Wiley.

Dewilde, C., \& Uunk, W. (2008). Remarriage as a way to overcome the financial consequences of divorce - A test of the economic need hypothesis for European women. European Sociological Review, 24(3), 393-407.

Dykstra, P. A., Kalmijn, M., Knijn, T. C. M., Komter, A. E., Liefbroer, A. C., \& Mulder, C. H. (2005). Codebook of the Netherlands Kinship Panel Study: A multi-actor, multi-method panel study on solidarity in family relationships, Wave 1. NKPS Working Paper No. 4. The Hague: Netherlands Interdisciplinary Demographic Institute.

England, P., \& McClintock, E. A. (2009). The gendered double standard of aging in US marriage markets. Population and Development Review, 35(4), 797-816.

Frazier, P., Arikian, N., Benson, S., Losoff, A., \& Maurer, S. (1996). Desire for marriage and life satisfaction among unmarried heterosexual adults. Journal of Social and Personal Relationships, 13(2), 225-239.

Ivanova, K., Kalmijn, M., \& Uunk, W. (2013). The effect of children on men's and women's chances of re-partnering in a European context. European Journal of Population/Revue européenne de Démographie. Prepublished July 10, 2013. DOI 10.1007/s 10680-013-9294-5.

Kelly, J. B. (2007). Children's living arrangements following separation and divorce: Insights from empirical and clinical research. Family process, 46(1), 35-52. 
Lampard, R., \& Peggs, K. (1999). Repartnering: the relevance of parenthood and gender to cohabitation and remarriage among the formerly married. The British journal of sociology, 50(3), 443-465.

Lichter, D. T., Anderson, R. N., \& Hayward, M. D. (1995). Marriage markets and marital choice. Journal of Family Issues, 16(4), 412-431.

Ní Bhrolcháin, M., \& Sigle-Rushton, W. (2005). Partner supply in Britain and the US. Population (english edition), 60(1), 37-64.

Oppenheimer, V. K. (1988). A theory of marriage timing. American Journal of Sociology, 94, $563-591$

Oppenheimer, V. K., Kalmijn, M., \& Lim, N. (1997).Men's career development and marriage timing during a period of rising inequality. Demography, 34, 311-330.

Parker, R. (1999).Repartnering following relationship breakdown. Family Matters, 53, 39-43.

Rosenthal, C. J. (1985). Kinkeeping in the familial division of labor. Journal of Marriage and the Family, 47, 965 - 974.

Roxburgh, S. (2002). Racing through life: The distribution of time pressures by roles and role resources among full-time workers. Journal of Family and Economic Issues, 23(2), $121-145$.

Skew, A., Evans, A., \& Gray, E. (2009). Repartnering in the United Kingdom and Australia. Journal of Comparative Family Studies, 40, 563-585.

South, S. J. (1991). Sociodemographic differentials in mate selection preferences. Journal of Marriage and the Family, 53, 928-940.

Stewart, S. D., Manning, W. D., \& Smock, P. J. (2003). Union formation among men in the US: Does having prior children matter?. Journal of Marriage and Family, 65(1), 90104. 
Sweeney, M. M. (1997). Remarriage of women and men after divorce: The role of socioeconomic prospects. Journal of Family Issues, 18(5), 479-502.

Sweeney, M.M. (2010) Remarriage and stepfamilies: Strategic sites for family scholarship in the 21st century. Journal of Marriage and Family, 72, $667-684$.

Van Hoorn, W. D. (2000). Glad to live alone or happier together. Diversity among young and middle-aged single people. Maandstatistiek van de bevolking, 48, 16-23.

Van Tilburg, T. (2006). Sociaal kapitaal in de derde en vierde levensfase. Geron, 8, 15-18.

Waite, L. J., \& Gallagher, M. (2000). The case for marriage: Why married people are happier, healthier, and better off financially. New York: Doubleday.

Wang, H., \& Amato, P. R. (2000). Predictors of divorce adjustment: Stressors, resources, and definitions. Journal of Marriage and Family, 62(3), 655-668.

Willitts, M., Benzeval, M., \& Stansfeld, S. (2004). Partnership history and mental health over time. Journal of Epidemiology and Community Health, 58(1), 53-58.

Wu, Z., \& Schimmele, C. M. (2005). Repartnering after first union disruption. Journal of Marriage and Family, 67(1), 27-36. 
Figure 1. Relational preferences by gender and relationship history: percentages expressing a desire to live together or to marry

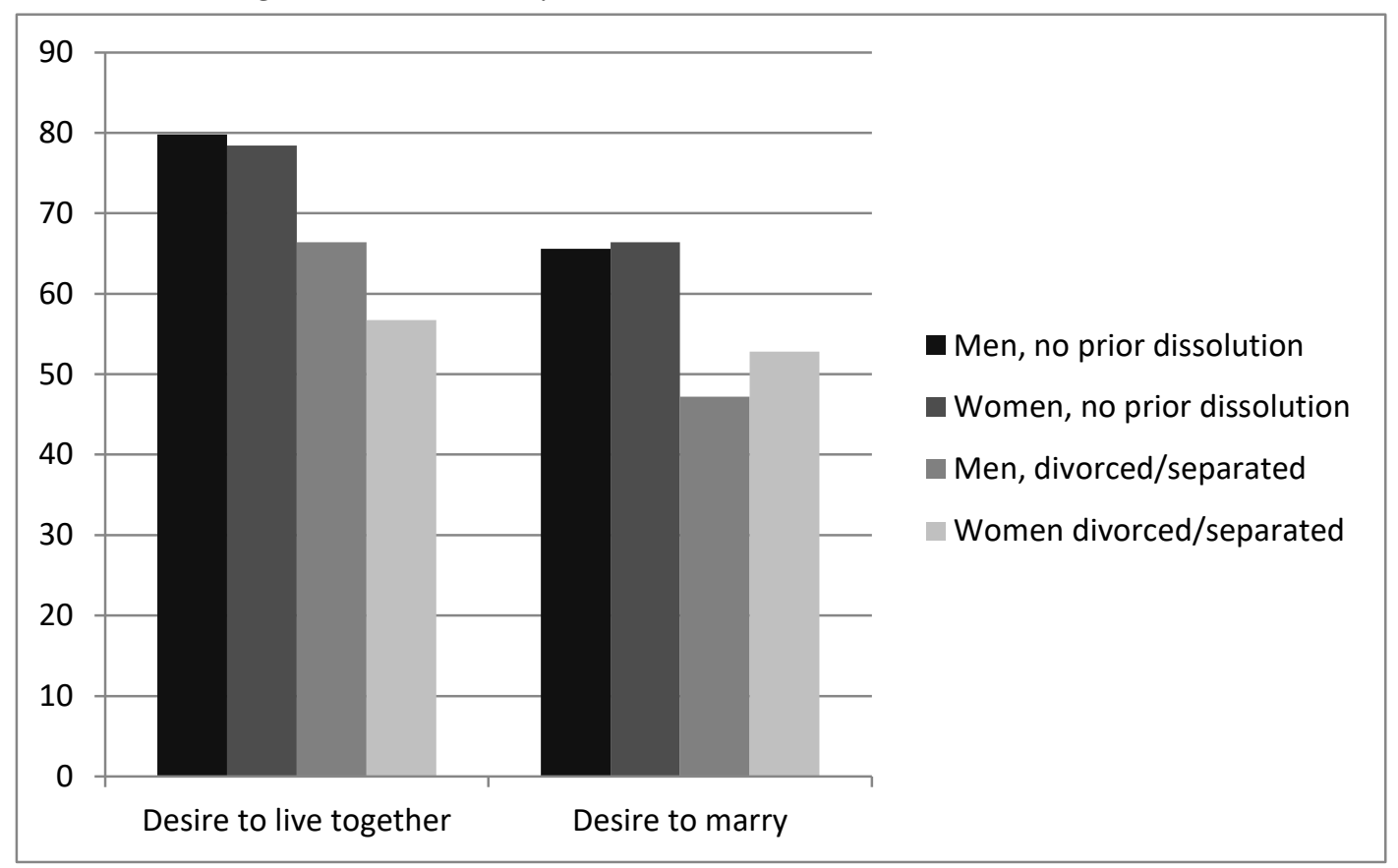

Note. Data are weighted 
Table 1. Descriptive statistics for the independent and control variables by gender and subsample: Means and t-values of test for gender differences

\begin{tabular}{|c|c|c|c|c|c|c|}
\hline & \multicolumn{2}{|c|}{ Sample 1} & \multicolumn{4}{|c|}{ Sample 2} \\
\hline & Men & Women & $\begin{array}{c}\text { T-value } \\
\text { gender } \\
\text { difference }\end{array}$ & Men & Women & $\begin{array}{c}\text { T-value } \\
\text { gender } \\
\text { difference }\end{array}$ \\
\hline \multicolumn{7}{|l|}{ Resources } \\
\hline Educational level & 12.37 & 12.17 & -0.85 & 12.73 & 12.58 & -0.68 \\
\hline Personal income/1000 & 1.76 & 1.21 & $-7.39 * *$ & 1.86 & 1.19 & $-8.73 * *$ \\
\hline Working hours & 29.32 & 20.84 & $-7.19 * *$ & 31.97 & 22.90 & $-7.59 * *$ \\
\hline \multicolumn{7}{|l|}{ Children } \\
\hline $\begin{array}{l}\text { Prior children present in } \\
\text { household }\end{array}$ & .13 & .46 & $8.76 * *$ & .08 & .35 & $7.31 * *$ \\
\hline $\begin{array}{l}\text { Age youngest child in } \\
\text { household a }^{\text {a }}\end{array}$ & 14.26 & 9.87 & $-4.37 * *$ & 14.23 & 9.53 & $-3.70 * *$ \\
\hline $\begin{array}{l}\text { Prior children outside } \\
\text { household }\end{array}$ & .37 & .17 & $-6.27 * *$ & .31 & .10 & $-6.35 * *$ \\
\hline $\begin{array}{l}\text { Contact with non-resident } \\
\text { children }{ }^{b}\end{array}$ & 47.76 & 65.78 & $1.81 \sim$ & 34.59 & 61.56 & $2.38^{*}$ \\
\hline Child support ${ }^{\mathrm{a}, \mathrm{b}}$ & .40 & .37 & -0.60 & .43 & .40 & -0.50 \\
\hline \multicolumn{7}{|l|}{ Current relationship status } \\
\hline Steady relationship & .24 & .25 & 0.35 & .20 & .21 & 0.32 \\
\hline Cohabiting & & & & .30 & .35 & 1.40 \\
\hline Relationship quality ${ }^{\mathrm{c}}$ & 4.26 & 4.10 & -1.08 & 4.41 & 4.28 & -0.56 \\
\hline \multicolumn{7}{|l|}{ Controls } \\
\hline Age & 42.05 & 40.45 & $-2.16^{*}$ & 39.58 & 36.59 & $-4.19 * *$ \\
\hline $\begin{array}{l}\text { Duration since } \\
\text { dissolution }\end{array}$ & 3.93 & 4.25 & 1.47 & 4.13 & 4.46 & 1.39 \\
\hline Type of dissolution & .52 & .58 & $1.66 \sim$ & .42 & .43 & 0.23 \\
\hline Religiosity & .35 & .45 & $2.61 * *$ & .33 & .44 & $2.73 * *$ \\
\hline $\mathrm{N}$ & 297 & 465 & & 271 & 377 & \\
\hline $\begin{array}{l}\text { Note. Gender differences are } \\
\text { regression (binary variables) } \\
\sim \mathrm{p} \leq .10 ; * \mathrm{p} \leq .05 ; * * \mathrm{p} \leq .01 \\
\mathrm{a} \text { Only if resident children } \\
\mathrm{b} \text { Only if non-resident childre } \\
{ }^{\mathrm{c}} \text { Only if steady or cohabiting }\end{array}$ & $\begin{array}{l}\text { on the in } \\
\text { ender be } \\
\text { ailed) }\end{array}$ & $\begin{array}{l}\text { ed data b } \\
\text { he indepe }\end{array}$ & $\begin{array}{l}\text { mple regress } \\
\text { ent variable. }\end{array}$ & continuo & & \\
\hline
\end{tabular}


Table 2. Logistic regression of desire to live together: unstandardized coefficients.

\begin{tabular}{|c|c|c|c|c|c|c|c|c|c|}
\hline & \multicolumn{5}{|l|}{ Full sample } & \multicolumn{2}{|l|}{ Single } & \multicolumn{2}{|c|}{ Steady relationship } \\
\hline & M1 & M2 & M3 & M4 & M5 & M1 & M5 & M1 & M5 \\
\hline Being a woman & $-.653 * *$ & $-.543 * *$ & $-.370 *$ & $-.610 * *$ & -.248 & $-.651 * *$ & -.271 & $-.703 \sim$ & -.522 \\
\hline \multicolumn{10}{|l|}{ Resources } \\
\hline Educational level & & $.067 *$ & & & .047 & & $.075^{*}$ & & -.015 \\
\hline Personal income/1000 & & .059 & & & .078 & & .109 & & -.015 \\
\hline Working hours & & .009 & & & .004 & & .000 & & .021 \\
\hline \multicolumn{10}{|l|}{ Prior children } \\
\hline Prior children in household & & & $-.986 * *$ & & $-.910 * *$ & & $-1.039 * *$ & & -.262 \\
\hline Age youngest resident child & & & $.051 *$ & & $.055^{*}$ & & $.066^{*}$ & & -.013 \\
\hline $\begin{array}{l}\text { Prior children outside } \\
\text { household }\end{array}$ & & & -.227 & & -.143 & & -.180 & & -.164 \\
\hline Contact non-resident child & & & $-.010 * *$ & & $-.009 *$ & & $-.013 * *$ & & -.003 \\
\hline Child support & & & .141 & & .004 & & .170 & & -.560 \\
\hline \multicolumn{10}{|l|}{ Current relationship status } \\
\hline Steady relationship & & & & $.519 *$ & $.445^{*}$ & & & & \\
\hline \multicolumn{10}{|l|}{ Cohabiting } \\
\hline Relationship quality & & & & $1.066 * *$ & $1.065 * *$ & & & & \\
\hline \multicolumn{10}{|l|}{ Controls } \\
\hline Age & $-.069 * *$ & $-.067 * *$ & $-.078 * *$ & $-.062 * *$ & $-.075 * *$ & $-.067 * *$ & $-.081 * *$ & $-.055^{*}$ & $-.058-$ \\
\hline Duration since dissolution & -.011 & -.008 & -.023 & -.029 & -.036 & -.018 & -.026 & -.074 & -.058 \\
\hline Type of dissolution & $-.546 * *$ & $-.492 * *$ & -.161 & $-.671 * *$ & -.264 & $-.724 * *$ & -.314 & .003 & .326 \\
\hline Religiosity & $.318 \sim$ & $.382 *$ & $.311 \sim$ & $.294 \sim$ & $.326 \sim$ & $.349 \sim$ & $.423^{*}$ & .409 & .498 \\
\hline $\mathrm{N}$ & 762 & 762 & 762 & 762 & 762 & 572 & 572 & 190 & 190 \\
\hline
\end{tabular}

Note. Current relationship status is not controlled for in the separate analyses for singles and respondents with a partner, because there is no within-group variation on these variables or because variables are not applicable (i.e. relationship quality for singles). If relationship quality is controlled for in the analyses for partnered respondents, the estimate if $1.102(\mathrm{p}<.01)$ for relationship quality and the estimate for gender becomes $-.247(\mathrm{p}=.612)$.

$\sim \mathrm{p} \leq .10 ; * \mathrm{p} \leq .05 ; * * \mathrm{p} \leq .01$ (two-tailed). 
Table 3. Logistic regression of desire to marry: unstandardized coefficients.

\begin{tabular}{|c|c|c|c|c|c|c|c|c|c|}
\hline & \multicolumn{4}{|c|}{ Full sample } & \multicolumn{3}{|c|}{ Single } & \multicolumn{2}{|c|}{$\begin{array}{l}\text { Steady relationship or } \\
\text { cohabiting }\end{array}$} \\
\hline & M1 & M2 & M3 & M4 & M5 & M1 & M5 & M1 & M5 \\
\hline Being a woman & -.066 & -.056 & .004 & -.068 & -.001 & .402 & $.551 \sim$ & $-.519 *$ & -.464 \\
\hline \multicolumn{10}{|l|}{ Resources } \\
\hline Educational level & & .030 & & & .032 & & .047 & & .023 \\
\hline Personal income/1000 & & -.003 & & & .016 & & .058 & & .048 \\
\hline Working hours & & .001 & & & -.000 & & -.004 & & -.002 \\
\hline \multicolumn{10}{|l|}{ Prior children } \\
\hline Prior children in household & & & .178 & & .255 & & .078 & & .259 \\
\hline Age youngest resident child & & & .031 & & .031 & & .017 & & .056 \\
\hline Prior children outside & & & .479 & & .531 & & -.367 & & .556 \\
\hline \multicolumn{10}{|l|}{ household } \\
\hline Contact non-resident child & & & -.006 & & -.006 & & $-.053 *$ & & -.003 \\
\hline Child support & & & $-.696^{*}$ & & $-.751 * *$ & & $-1.196^{*}$ & & -.469 \\
\hline \multicolumn{10}{|l|}{ Current relationship status } \\
\hline Steady relationship & & & & $.449 \sim$ & $.437 \sim$ & & & & \\
\hline Cohabiting & & & & .201 & .190 & & & & \\
\hline Relationship quality & & & & .200 & .212 & & & & \\
\hline \multicolumn{10}{|l|}{ Controls } \\
\hline Age & $-.090 * *$ & $-.091 * *$ & $-.101 * *$ & $-.088 * *$ & $-.102 * *$ & $-.087 * *$ & $-.095 * *$ & $-.097 * *$ & $-.115 * *$ \\
\hline Duration since dissolution & $.081 * *$ & $.084 * *$ & $.077 *$ & $.066^{*}$ & $.066^{*}$ & $.132 * *$ & $.120 *$ & .022 & .022 \\
\hline Type of dissolution & -.196 & -.152 & -.102 & -.232 & -.107 & $-.851 * *$ & -.590 & .337 & .393 \\
\hline Religiosity & $.472 *$ & $.482 * *$ & $.449 *$ & $.470 *$ & $.458^{*}$ & .396 & .401 & $.561 *$ & $.544 *$ \\
\hline $\mathrm{N}$ & 648 & 648 & 648 & 648 & 648 & 304 & 304 & 344 & 344 \\
\hline
\end{tabular}

Note. Current relationship status is not controlled for in the separate analyses for singles and respondents with a partner, because there is no within-group variation on these variables or because variables are not applicable (i.e. relationship quality for singles). If cohabitation and relationship quality are controlled for in the analyses for partnered respondents, the estimate is $-.180(\mathrm{p}=.466)$ for cohabitation and $.176(\mathrm{p}=.312)$ for relationship quality and the estimate for gender becomes $-.476(\mathrm{p}=.105)$.

$\sim \mathrm{p} \leq .10 ; * \mathrm{p} \leq .05 ; * * \mathrm{p} \leq .01$ (two-tailed). 
Table 4. Logistic regression of desire to live together and of desire to marry by gender: unstandardized coefficients.

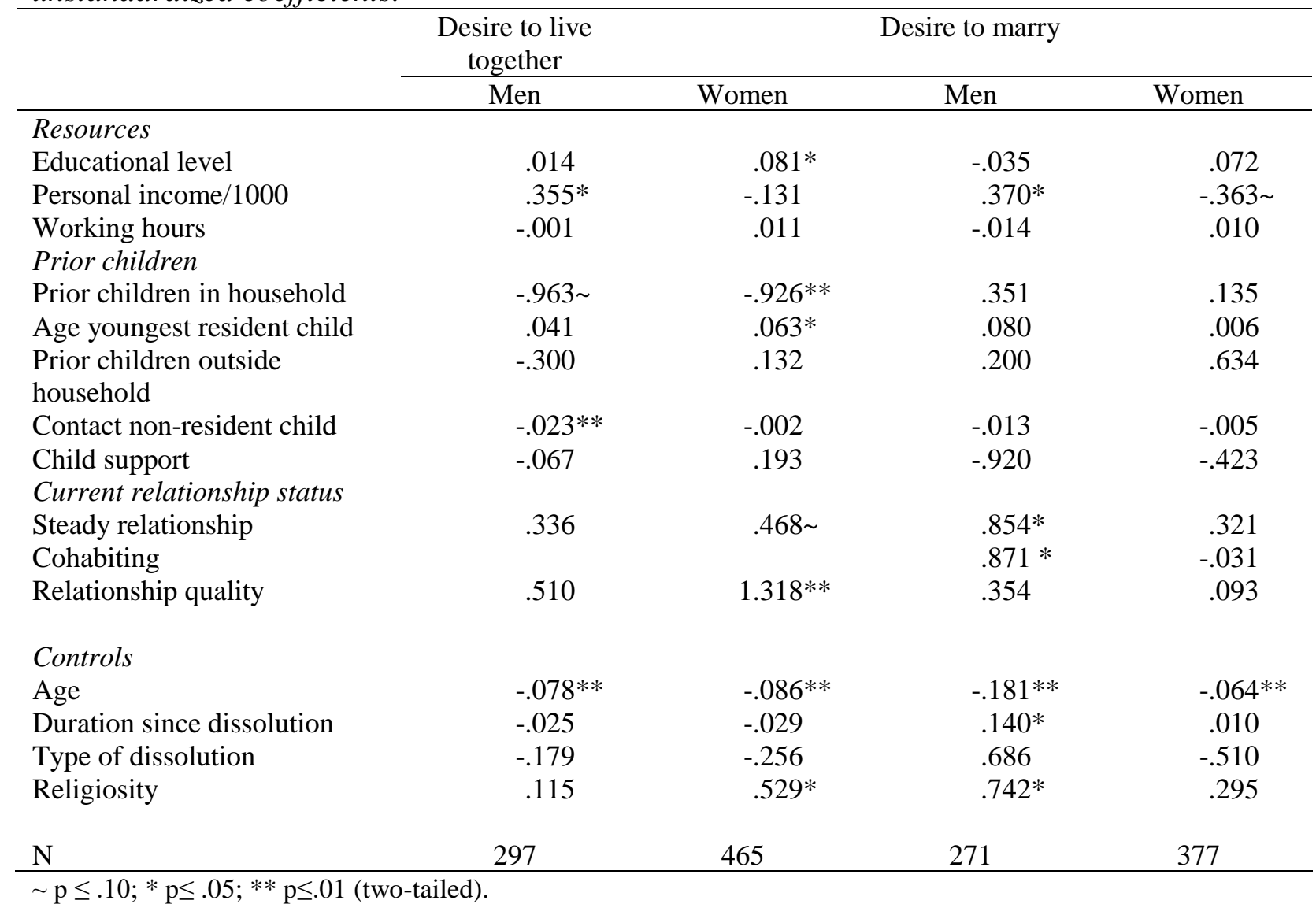

